\title{
Flux calculation of short turbulent events - comparison of three methods
}

\author{
Carsten Schaller $^{1,2, a}$, Mathias Göckede ${ }^{2}$, and Thomas Foken ${ }^{1,3}$ \\ ${ }^{1}$ University of Bayreuth, former Department of Micrometeorology, 95440 Bayreuth, Germany \\ ${ }^{2}$ Max-Planck-Institute for Biogeochemistry, Dept. Biogeochemical Systems, 07745 Jena, Germany \\ ${ }^{3}$ University of Bayreuth, Bayreuth Center of Ecology and Environmental Research (BayCEER), 95440 Bayreuth, Germany \\ ${ }^{a}$ now at: University of Münster, Institute of Landscape Ecology, Climatology Group, Heisenbergstr. 2, 48149 Münster, \\ Germany
}

Correspondence to: Carsten Schaller (carsten.schaller@uni-muenster.de)

Received: 1 August 2016 - Discussion started: 12 September 2016

Revised: 25 January 2017 - Accepted: 1 February 2017 - Published: 9 March 2017

\begin{abstract}
The eddy covariance method is commonly used to calculate vertical turbulent exchange fluxes between ecosystems and the atmosphere. Besides other assumptions, it requires steady-state flow conditions. If this requirement is not fulfilled over the averaging interval of, for example, $30 \mathrm{~min}$, the fluxes might be miscalculated. Here two further calculation methods, conditional sampling and wavelet analysis, which do not need the steady-state assumption, were implemented and compared to eddy covariance. All fluxes were calculated for $30 \mathrm{~min}$ averaging periods, while the wavelet method - using both the Mexican hat and the Morlet wavelet - additionally allowed us to obtain a 1 min averaged flux.

The results of all three methods were compared against each other for times with best steady-state conditions and well-developed turbulence. An excellent agreement of the wavelet results to the eddy covariance reference was found, where the deviations to eddy covariance were of the order of $<2 \%$ for Morlet as well as $<7 \%$ for Mexican hat and thus within the typical error range of eddy covariance measurements. The conditional sampling flux also showed a very good agreement to the eddy covariance reference, but the occurrence of outliers and the necessary condition of a zero mean vertical wind velocity reduced its general reliability. Using the Mexican hat wavelet flux in a case study, it was possible to locate a nightly short time turbulent event exactly in time, while the Morlet wavelet gave a trustworthy flux over a longer period, e.g. $30 \mathrm{~min}$, under consideration of this short-time event.
\end{abstract}

At a glance, the Mexican hat wavelet flux offers the possibility of a detailed analysis of non-stationary times, where the classical eddy covariance method fails. Additionally, the Morlet wavelet should be used to provide a trustworthy flux in those $30 \mathrm{~min}$ periods where the eddy covariance method provides low-quality data due to instationarities.

\section{Introduction}

The eddy covariance technique is a common method to measure vertical turbulent exchange fluxes between ecosystems and the atmosphere. It has the great advantage of being a direct and in situ measurement method (Aubinet et al., 2012) integrating over ecosystem scale without disturbing it significantly. However, eddy covariance requires important assumptions to be fulfilled, e.g. steady-state flow conditions and horizontal homogeneity. Mainly under conditions of stable stratification and due to a possible violation of the steadystate assumption, the fluxes might be miscalculated by eddy covariance, which needs an averaging period of about $30 \mathrm{~min}$ to resolve a turbulent flux properly. Typical cases that lead to low data quality include, for example, microfronts or intermitted turbulence.

The application of wavelet analysis became popular in geoscience and atmospheric turbulence at the beginning of the 1990s (Farge, 1992; Kumar and Foufoula-Georgiou, 1997; Torrence and Compo, 1998). First they were used to detect jumps of turbulent motions (Mahrt, 1991) or 
the duration of turbulent events including filtering analysis (Collineau and Brunet, 1993a, b). The application of the spectra of the wavelet coefficient (Collineau and Brunet, 1993b; Treviño and Andreas, 1996) offered also the possibility to determine turbulent fluxes (Katul and Parlange, 1995; Handorf and Foken, 1997; Saito and Asanuma, 2008). With the availability of wavelet software packages in the last 20 years all these methods have become more popular, and have been used for applications such as the detection of turbulent structures (Thomas and Foken, 2005) or turbulent fluxes of aircraft measurements (Strunin and Hiyama, 2004) and at forested sites (Thomas and Foken, 2007). The method was also applied to improve the frequency correction of eddy covariance measurements (Nordbo and Katul, 2013).

Conditional sampling is furthermore applicable under non-steady conditions and was proposed by Desjardins (1977) as an experimental approach for trace gas measurements. Due to a lack of quick response valve control technology it was impossible to find a practical realization in Desjardin's days. Today it is available as a mathematical tool for flux calculations in the case of coherent structures (Antonia, 1981; Collineau and Brunet, 1993b; Thomas and Foken, 2007).

Until now no direct comparisons of the eddy covariance method with results obtained by wavelet analysis and conditional sampling for long-time periods of methane fluxes had been conducted. Therefore, the challenge of this paper is not only the comparison of both already often-applied methods in relationship to the eddy covariance method but also to show with two examples that the quality test for eddy covariance data (Foken and Wichura, 1996) is a good tool to filter non-steady-state time series for which the wavelet or conditional sampling tools are alternative flux calculation methods.

\section{Material and methods}

\subsection{Data basis and instrumentation}

The data used for this work were obtained from June to September 2014 at a study site located approximately $15 \mathrm{~km}$ south of the settlement Chersky $\left(68.613^{\circ} \mathrm{N}, 161.342^{\circ} \mathrm{E} ; 6 \mathrm{~m}\right.$ above sea level) in the Sakha (Yakutia) Republic, Far Eastern Federal District of Russia, about $150 \mathrm{~km}$ south of the East Siberian Sea. It is part of the flat floodplains of the Kolyma river and situated in an area of continuous permafrost. Climatically the area can be described as continental with a dry, warm and short summer from June to August as well as a long, extremely cold winter.

An eddy covariance system has been running continuously since July 2013. The measurements were conducted using the heatable 3-D sonic anemometer USA-1 (Metek GmbH, Elmshorn, Germany) combined with a closed-path setup, where the inlet of the gas tube was fixed directly below the sonic anemometer. This tube (Eaton Synflex decabon, length $13.8 \mathrm{~m}$, Reynolds number $R e>2300$ ) was connected to the gas analyser FGGA-24r-EP by Los Gatos Research (Mountain View, California, USA) for $\mathrm{H}_{2} \mathrm{O}, \mathrm{CO}_{2}$ and $\mathrm{CH}_{4}$, which was installed in a nearby wooden cabin. The concentration expressed as wet mole fraction in the raw data collected by the gas analyser was converted to dry mole fraction immediately, thus the results are independent of changes in temperature and humidity. The aerodynamic height of the USA-1 was $5.41 \mathrm{~m}$ above zero-plane displacement due to the existing tussocks. The tower was supplied with electric power by a fuel powered generator located at the shore of Ambolyka river, a tributary of river Kolyma.

\subsection{Data processing and quality control for all methods}

The raw data from the sonic anemometer and the closed-path analyser were collected by the software EDDYMEAS (Kolle and Rebmann, 2007) at a sampling rate of $20 \mathrm{~Hz}$, while all other meteorological data were collected using the CR3000 Micrologger combined with the software LoggerNet (Campbell Scientific Inc., Logan, Utah, USA). Both software programs were running on a personal computer located together with the gas analyser in the wooden cabin. All data refer to local time, where Chersky was covered by Magadan time, i.e. coordinated universal time (UTC) $+12 \mathrm{~h}$. The mean local solar noon is UTC $+13 \mathrm{~h}$.

As the present work aimed in a methodological comparison of different flux calculation methods, the early preprocessing for all three methods was done identically using the software TK3 (Mauder and Foken, 2015b), first of all consisting of the conversion from electrical voltage to actual physical units and the detection of spikes. Using the median absolute deviation (MAD)

$\mathrm{MAD}=\left\langle\left|x_{i}-\langle x\rangle\right|\right\rangle$,

where $\langle x\rangle$ describes the median of $x$, a spike test

$\langle x\rangle-\frac{q \cdot \mathrm{MAD}}{0.6745} \leq x_{i} \leq\langle x\rangle+\frac{q \cdot \mathrm{MAD}}{0.6745}$

was conducted, where the threshold value was $q=7$ and the value 0.675 corresponds to the Gaussian distribution (Hoaglin et al., 2000). Values $x_{i}$ exceeding the given range in expression (2) were labelled as spike, removed and linearly interpolated. Afterwards the $20 \mathrm{~Hz}$ concentration and vertical wind speed data were cross-correlated to correct time delays between the sensors. Coordinate rotation was not applied due to the very flat terrain, so over typical time periods for the planar fit rotation (Wilczak et al., 2001) $\bar{w}=0$ can be assumed also without rotation. After these preliminary steps, the covariance was calculated using the three different methods of eddy covariance (Sect. 2.3), conditional sampling (Sect. 2.4) and wavelet analysis (Sect. 2.5).

In order to obtain the finalized flux, a number of additional corrections should be applied to the calculated covariance, e.g. the transformation of the measured buoyancy flux 
into the sensible heat flux (Schotanus et al., 1983) as well as a spectral correction in the high-frequency range (Moore, 1986) and the WPL correction (Webb et al., 1980), which accounts for non-negligible density fluctuations. As the corrections are identical for all calculation methods, their application was omitted for the present methodological study. It should be noted that these omitted corrections are necessary to obtain the real ecosystem exchange.

\subsection{Eddy covariance method}

The eddy covariance method is based on the turbulent Navier-Stokes equation (Stull, 1988) of mean motion for turbulent flow and allows direct flux measurements, i.e. for flux calculation empirical constants are not necessary (Foken, 2016). Therefore, the covariance of the vertical wind speed $w$ and the concentration $c$ can be calculated as

$\overline{w^{\prime} c^{\prime}}=\frac{1}{N-1} \sum_{k=0}^{N-1}\left[\left(w_{k}-\bar{w}\right) \cdot\left(c_{k}-\bar{c}\right)\right]$.

Particularly important assumptions are fully developed turbulent flow as well as horizontal homogeneity of the surface and thus the flow field (Foken and Wichura, 1996; Foken et al., 2012).

For this study the program TK3, version 3.11 (Mauder and Foken, 2015a) well-compared to other processing tools (Mauder et al., 2008; Fratini and Mauder, 2014), was used. It conducts the covariance calculation and also allows application of data quality tools (Foken and Wichura, 1996) on the results.

\subsection{Conditional sampling}

The conditional sampling method - also known as eddy accumulation - is based on Desjardins (1977), where the covariance $\overline{w^{\prime} c^{\prime}}$ of a turbulent flux can be calculated as

$\overline{w^{\prime} c^{\prime}}=\overline{w^{+} c}+\overline{w^{-} c}=\left(\overline{w^{+}}+\overline{w^{-}}\right) \cdot \bar{c}+\overline{w^{+} c^{\prime}}+\overline{w^{-} c^{\prime}}$

with mean vertical wind $\bar{w}=\left(\overline{w^{+}}+\overline{w^{-}}\right)=0$. Expressed in words, within an averaging period, e.g. $30 \mathrm{~min}$, the gas concentrations for up- and downwind situations are stored separately and weighted with the associated vertical wind velocity. The flux is then calculated for both storages, which are summed up afterwards over the averaging period. Using data from an eddy covariance tower, the conditional sampling method provides a second possibility for direct flux investigation, while the assumptions to be considered are the same.

In the present study the conditional sampling flux was calculated following Eq. (4), where the mean vertical wind $\bar{w}$ was obtained using the block-averaging method (Finnigan et al., 2003; Rebmann et al., 2012)

$\bar{w}=\frac{1}{N} \cdot \sum_{n=1}^{N} w_{n}$ in intervals corresponding exactly to eddy covariance of $\Delta t=30 \mathrm{~min}$. Because $\bar{w}$ according to Eq. (5) was almost exactly 0 in the flat terrain, no coordinate rotation was necessary to fulfil the conditions for Eq. (4).

\subsection{Wavelet analysis}

The wavelet transform allows the decomposition of a time series into the frequencies that represent the signal without losing information about its localization in time (Torrence and Compo, 1998; Percival and Walden, 2008).

A continuous wavelet transform of a discrete time series $x(t)$ can be written as convolution of $x(t)$,

$T(a, b)=\int_{-\infty}^{\infty} x(t) \cdot \psi_{a, b}^{*}(t) \mathrm{d} t$,

where $T(a, b)$ is the wavelet coefficient and $\psi_{a, b}(t)$ is referred to as wavelet function

$\psi_{a, b}(t)=\frac{1}{\sqrt{a}} \cdot \psi\left(\frac{t-b}{a}\right)$,

which includes the wavelet $\psi$ and requires a dilation parameter $a$ as well as a translation parameter $b$. The latter parameter indicates the temporal position of the wavelet in the time series, while $a$ controls the scale of the wavelet and thus the current frequency of interest. If the chosen wavelet is complex-valued, then the complex conjugate $\psi_{a, b}^{*}(t)$, denoted by a star sign, is used.

In this study wavelets with a sinusoidal form were used, where especially the complex-valued Morlet wavelet has been proven to be an appropriate choice for atmospheric turbulence (e.g. Thomas and Foken, 2005; Strunin and Hiyama, 2004; Terradellas et al., 2001) and can be expressed as

$\psi^{M}(u) \approx \psi_{\omega_{0}}^{M}(u) \equiv \pi^{-\frac{1}{4}} \cdot e^{-i \omega_{0} u} \cdot e^{-\frac{u^{2}}{2}}$,

where $\omega_{0}=6$, which results in a sufficient accuracy (Farge, 1992) and $u=\frac{t-b}{a}$. While the strengths of the Morlet wavelet are in a very good localization in the frequency domain, the advantage of the Mexican hat wavelet is on edge detection and provides an exact localization of single events in time (e.g. Collineau and Brunet, 1993a). Based on the second derivative of a Gaussian probability density function (Percival and Walden, 2008), the Mexican hat wavelet can be expressed as

$\psi^{M h}(u) \equiv \frac{2 \cdot\left(1-\frac{u^{2}}{\sigma^{2}}\right) \cdot e^{-\frac{u^{2}}{2 \sigma}}}{\pi^{\frac{1}{4}} \cdot \sqrt{3 \cdot \sigma}}=\frac{2}{\pi^{\frac{1}{4}} \cdot \sqrt{3}} \cdot\left(1-u^{2}\right) \cdot e^{-\frac{u^{2}}{2}}$

with $\sigma=1$.

The expression $T^{2}(a, b)$ across all times and scales provides the total energy of the time series and the average of the 
wavelet scalogram $\left|T^{2}(a, b)\right|$ is used to obtain the wavelet spectrum (Torrence and Compo, 1998)

$$
E_{x}(j)=\frac{\delta t}{C_{\delta}} \cdot \frac{1}{N} \cdot \sum_{n=0}^{N-1}\left|T^{2}(a, b)\right|
$$

over a given number $N$ of values in the time series, taking the time step $\delta t$ and a wavelet-specific reconstruction factor $C_{\delta}$ into account. From this it is now possible to obtain the global variance of the time series by integrating over all scales $j=0$ to $J$

$\sigma_{x}^{2}=\frac{\delta t}{C_{\delta}} \cdot \frac{\delta j}{N} \cdot \sum_{n=0}^{N-1} \sum_{j=0}^{J} \frac{\left|T^{2}(a, b)\right|}{a(j)}$,

with $\delta j$ referring to the spacing between discrete scales and $J$ being the maximum number of scales. It should be noted that the wavelet scale is not equal to the Fourier period $\lambda$, i.e. the inverse frequency, but depends on the chosen wavelet $\psi$.

For two simultaneously recorded time series $x(t)$ and $y(t)$ the wavelet cross spectrum can now be obtained in analogy to Eq. (10) as

$E_{x y}(j)=\frac{\delta t}{C_{\delta}} \cdot \frac{1}{N} \cdot \sum_{n=0}^{N-1}\left[T_{x}(a, b) \cdot T_{y}^{*}(a, b)\right]$

where $T_{y}^{*}(a, b)$ denotes the complex conjugate of the wavelet transform of the second time series $y(t)$ (Hudgins et al., 1993). Summing up over all scales yields the covariance (Stull, 1988)

$\overline{x^{\prime} y^{\prime}}=\frac{\delta t}{C_{\delta}} \cdot \frac{\delta j}{N} \cdot \sum_{n=0}^{N-1} \sum_{j=0}^{J} \frac{\left[T_{x}(a, b) \cdot T_{y}^{*}(a, b)\right]}{a(j)}$

for the chosen averaging interval. If the chosen time series $x$ and $y$ are the vertical wind velocity $w$ and a corresponding gas concentration $c$, the flux $\overline{w^{\prime} c^{\prime}}$ can be calculated now using Eq. (13). Wavelet analysis offers the possibility to calculate fluxes over short averaging times, which are defined by choosing a proper summation interval $n$ to $N-1$ in Eqs. (12) and (13). Due to the transformation into scale and time domain, low-frequency flux contributions are not neglected; nevertheless it is also possible to include only a subset of frequencies by limiting the summation interval $j$ to $J$ in Eq. (13).

As the intention of this study was on short events as well as a comparison to the traditional eddy covariance method, the wavelet cross-spectrum was calculated for both averaging intervals $\Delta t=1 \mathrm{~min}$ and $\Delta t=30 \mathrm{~min}$. In the last step to obtain the final wavelet flux the cross-wavelet spectrum was integrated over the scales following Eq. (13). Calculating the equivalent to the averaging time for the eddy covariance calculation of $30 \mathrm{~min}$, the scale integration interval was set from the smallest equivalent period to 33 and $34 \mathrm{~min}$ for Mexican hat and Morlet wavelet, respectively. The difference of 3 and 4 min arises out of the wavelet-dependent calculation of the period $\lambda$ and the choice of the spacing parameter $\delta j$. Here, as a compromise between good resolution in frequency domain and required amount of random access memory (RAM) $\delta j$ was set to $0.25 \mathrm{~s}$.

\subsection{General survey of the flux investigation methods}

Although the eddy covariance method has been proven as the highly accurate standard, the wavelet analysis allows us to neglect two main requirements of eddy covariance: at first, the time averaging can be smaller than 10 to $30 \mathrm{~min}$ due to wavelet decomposition in time and frequency domain without ignoring flux contributions in the low-frequency range. Secondly, wavelet transform does not require steady-state conditions, but can also be applied on time series containing non-stationary power (e.g. Terradellas et al., 2001; Strunin and Hiyama, 2004). On the other hand, the calculation of fluxes using wavelet transform requires considerably higher amount of computational resources, even when a windowed approach is used. In contrast, conditional sampling still requires an averaging interval analogously to eddy covariance, but there is no need to satisfy the steady-state condition provided that $\bar{w}=0$ was chosen absolutely correct, which might be extremely difficult. Table 1 summarizes basic characteristics of each method, as well as specific strengths and weaknesses.

\subsection{Quality control}

In order to compare the three calculation methods, no more corrections were applied, but a second run of the TK3 routine was executed to provide quality assessments. It included double rotation, spectral correction in the high-frequency range (Moore, 1986) as well as a crosswind correction of the sonic acoustic temperature after Schotanus et al. (1983). As the raw concentration data were already converted into dry mole fraction, the WPL correction (Webb et al., 1980) was not applied to the data. This corrected data set was needed to select times with best steady-state conditions and well-developed turbulence. This was done to ensure that the comparison of the three methods is based on steady-state data with welldeveloped turbulence, which is recommended for the eddy covariance method. For the stationarity test, the mean covariance derived from $5 \mathrm{~min}$ intervals was compared to the covariance of the whole $30 \mathrm{~min}$ interval (Foken and Wichura, 1996) and best conditions were assumed, if the difference was not greater than $30 \%$. The integral turbulence characteristics (ITC) describe the current state of the atmospheric turbulence integral over the frequency spectrum and can be modelled using parametrisations, based on the concept of flux-variance similarity, and depend on the atmospheric stability (Foken et al., 2004). In the case of a well-developed tur- 
Table 1. Summary evaluation of eddy covariance, conditional sampling and wavelet analysis method.

\begin{tabular}{|c|c|c|c|}
\hline & Eddy covariance & Conditional sampling & Wavelet analysis \\
\hline Sampling rate & $10-20 \mathrm{~Hz}$ & $10-20 \mathrm{~Hz}$ & $10-20 \mathrm{~Hz}$ \\
\hline $\begin{array}{l}\text { Time resolution of } \\
\text { calculated flux }\end{array}$ & $10-60 \mathrm{~min}$ & $10-60 \mathrm{~min}$ & $\begin{array}{l}<1 \mathrm{~s}-60 \mathrm{~min} \text { (Nyquist } \\
\text { frequency restricts lower } \\
\text { limit) }\end{array}$ \\
\hline Turbulent conditions & required & required & required \\
\hline Stationarity/steady state & required & $\begin{array}{l}\text { depends on method to } \\
\text { obtain } \bar{w}=0\end{array}$ & not necessary \\
\hline Computing requirements & $\begin{array}{l}\text { standard personal co- } \\
\text { mputer, ready to use pro- } \\
\text { cessing software available }\end{array}$ & standard personal computer & $\begin{array}{l}\text { memory intensive calcula- } \\
\text { tion, RAM } \geq 8 \text { GB recom- } \\
\text { mendable }\end{array}$ \\
\hline Standard software & $\begin{array}{l}\text { available from several } \\
\text { sources, e.g. TK3 (Mauder } \\
\text { and Foken, 2015b), } \\
\text { EddySoft (Kolle and Reb- } \\
\text { mann, 2007) }\end{array}$ & not available & $\begin{array}{l}\text { not available, but programs } \\
\text { to conduct basic wavelet } \\
\text { transform already exist, } \\
\text { e.g. R-biwavelet (Gouhier, } \\
\text { 2014) }\end{array}$ \\
\hline
\end{tabular}

bulence, the difference of modelled and measured ITC was not greater than $30 \%$.

\subsection{Selection of non-steady-state events}

In order to detect short-time turbulent events, a MAD spike test similar to Papale et al. (2006) using Eq. (2) was conducted, where

$x_{i}=\left(y_{i}-y_{i-1}\right)-\left(y_{i+1}-y_{i}\right)$

parametrises the change $x_{i}$ in flux $y$ over time. If there is no change in slope from $t_{i-1}$ over $t$ to $t_{i+1}$, then $x_{i}=0$. Positive peaks as well as increasing slopes lead to $x_{i}>0$, negative peaks and decreasing slopes to $x_{i}<0$. Due to its robustness, the MAD is a very good measure of the variability of a time series and substantially more resilient to outliers than the standard deviation (Hoaglin et al., 2000). The test was applied on the Mexican hat wavelet flux with a time step of $\Delta t=30 \mathrm{~min}$. If a value $x_{i}$ in the time series exceeded the given range in Eq. (2), it was detected as an interval containing an event. As the measuring period started in Arctic spring and ended in Arctic autumn, the test was not applied on the whole data set, but in consecutive steps of 15 days to minimize seasonal influences. A threshold value of $4 \leq q \leq 6$ in Eq. (2) was found to be suitable to resolve the location of such events in time.

\subsection{Validation of the results}

For result validation of the methane flux a statistical evaluation using the concept of linear orthogonal regression (Dunn, 2004) was conducted. As the assumption of normally distributed residuals and a homogeneity of their variance, i.e. homoscedasticity, was not fulfilled, the coefficient of determination $R^{2}$ was obtained using the nonparametric Spearman's rank correlation coefficient (Hollander and Wolfe, 1973). As the permissibility of further statistics on the linear regression would require a transformation of the data, e.g. using a logarithm or the square root in order to fulfil the abovementioned assumptions, no more tests were conducted. To give anyhow a rough estimate of the maximum standard deviation of the modelled correlation, $\sigma_{x}$ and $\sigma_{y}$ was calculated as

$\sigma_{y}=\sqrt{\frac{\sum \epsilon_{y}^{2}}{n-2}}, \quad \sigma_{x}=\sqrt{\frac{\sum \epsilon_{x}^{2}}{n-2}}$,

assuming $x$ and $y$ being the causal (predictor) variable, respectively. The denominator $n-2$ takes the reduction of the degrees of freedom by the two variables $x$ and $y$ into account, while the residuals $\epsilon$ were calculated as

$\epsilon_{y}=y-\hat{y}, \quad \epsilon_{x}=x-\hat{x}$.

\section{Results}

\subsection{Comparison of the methods for steady-state and turbulent conditions}

An evaluation of the quality of the calculated results of both newly implemented methods for conditional sampling and wavelet fluxes was necessary to be sure that they are reliable. In this section all results were validated against each other for times with best steady-state conditions and well-developed turbulence as described in detail in Sect. 2.3. While the data availability over the whole measuring period was $92.2 \%$, 
about $57 \%(1292 \mathrm{~h})$ of the data in the captured time satisfied the stationarity and turbulence requirements mentioned above. All validation results refer to an averaging time of $\Delta t=30 \mathrm{~min}$ for all methods as well as to Fourier periods (see Table 1 in Torrence and Compo, 1998) of $\lambda \leq 33 \mathrm{~min}$ for Mexican hat and $\lambda \leq 34 \mathrm{~min}$ for Morlet fluxes. The use of nearly identical Fourier periods for both wavelets leads to different maximum timescales of about $8 \mathrm{~min}$ for the Mexican hat and $32 \mathrm{~min}$ for the Morlet wavelet. To check, whether fluxes at $1 \mathrm{~min}$ intervals can directly be compared in the context of this study, the period of the Morlet wavelet was multiplied by a factor of 3 . Comparing both methods for the steady-state subset of the data within a 3-week period demonstrated that this approach yields differences of less then $1 \%$ of the measured flux, which is much lower then the typical error of the eddy covariance method.

\subsubsection{Conditional sampling vs. eddy covariance}

In comparison to wavelet analysis, only for conditional sampling $17(0.7 \%)$ outliers were found and consequently removed by adaption of the MAD test $(q=5)$ from Eq. (2) on the orthogonal residuals. These outliers were found only for eddy covariance fluxes up to $0.5 \mathrm{nmol} \mathrm{mol}{ }^{-1} \mathrm{~m} \mathrm{~s}^{-1}$ and thus the greater the eddy covariance reference flux, the better the results of both methods coincided.

Besides the found outliers, the very good regression slope of $m=0.989$ (Fig. 1) and coefficient of determination $R^{2}=$ 0.978 confirmed a good agreement between eddy covariance and conditional sampling. Unfortunately, the occurrence of values with bad quality (outliers) even under best steady-state conditions and well-developed turbulence makes the general use problematic, but a general dependency between single meteorological parameters and the occurrence of extreme conditional sampling spikes was not found. The reason for these outliers gets explainable, when taking the method's use of $w$ into account: eddy covariance and wavelet analysis both base on the correlation between $w$ and $c$, for eddy covariance there is the additional requirement of $\bar{w} \bar{c}=0$ over the averaging period or in the long term (Wilczak et al., 2001). However, in the conditional sampling method $\bar{w}$ is directly taken into account in Eq. (4). In consequence there is a strong dependency on an absolutely correct chosen value for the mean vertical wind $\bar{w}$, where even small inaccuracies lead to a flux bias.

\subsubsection{Wavelet analysis vs. eddy covariance}

\section{Comparison of Morlet against Mexican hat wavelet flux}

The main difference between the Mexican hat and Morlet wavelet is the excellent resolution in the time domain at the first (see also Fig. 4, third panel) and in the frequency domain at the second wavelet (Fig. 4, second panel). As the spacing between the discrete wavelet scales, $\delta j=0.25 \mathrm{~s}$, was chosen

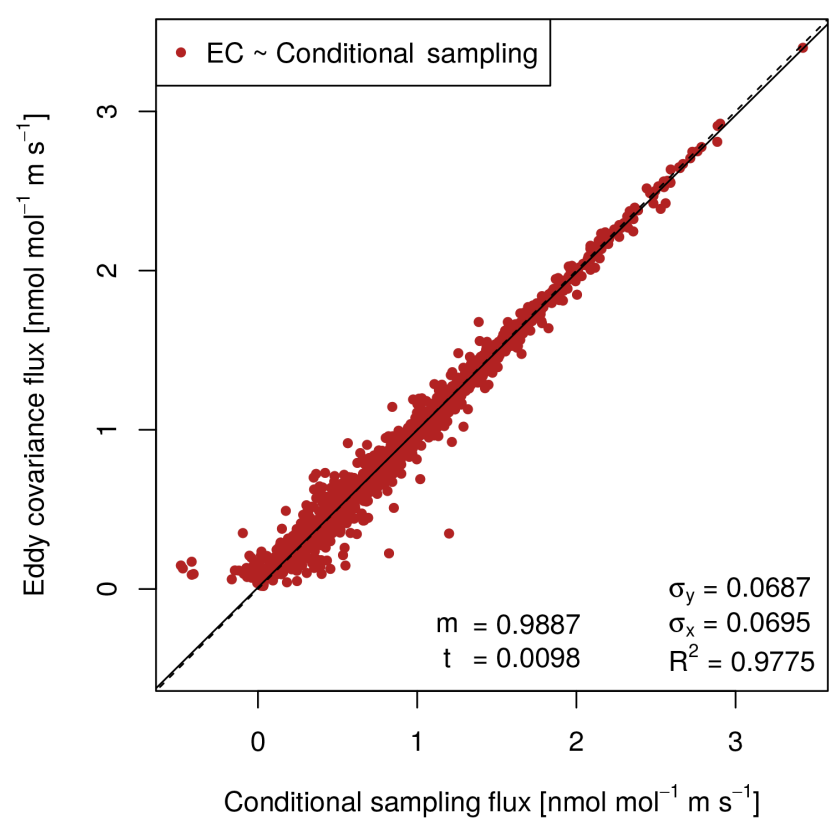

Figure 1. Scatterplot of conditional sampling against eddy covariance methane flux for times with best steady-state conditions and well-developed turbulence. The dashed line follows the function $f(x)=x$ and the solid one is the orthogonal regression line.

small enough, a very good agreement between the results of both wavelets was expected and at last also observed (Fig. 2). The mean regression line has a slope of $m=0.979$ as well as an intercept of $t=-0.010$ and thus it coincides nearly perfectly with the line through origin of slope 1 .

About $99.5 \%$ of the variance in the results of each method can be explained by the linear relationship. Theoretically deciding for a predictor variable, the standard deviations for $x$ or $y$ being independent nearly coincide, where $\sigma_{y}=$ $0.036 \mathrm{nmol} \mathrm{mol}^{-1} \mathrm{~m} \mathrm{~s}^{-1}$ and $\sigma_{x}=0.037 \mathrm{nmol} \mathrm{mol}^{-1} \mathrm{~m} \mathrm{~s}^{-1}$ for $\mathrm{CH}_{4}$ flux. All in all it can be summarized that - except for a few negligible outliers - the fluxes are almost identical under consideration of the residuals standard deviation.

\section{Comparison of wavelet fluxes against eddy covariance flux}

In contrast to the comparison of the two wavelet methods, the validation of both against the eddy covariance flux determined the actual quality of the calculated results, because the latter is considered the reference standard in the context of this study. For each wavelet (Fig. 3) a slope of $m \approx 1$ was detected, where the Morlet wavelet showed a closer agreement with the ideal slope (1.023) than the Mexican hat (1.045). The deviations between the eddy covariance and wavelet results were of the order of $<2 \%$ for Morlet as well as $<7 \%$ for Mexican hat and therefore within the range of the typical error in eddy covariance measurements and processing of about 5 to $10 \%$ (Mauder et al., 2006, 2007b). 


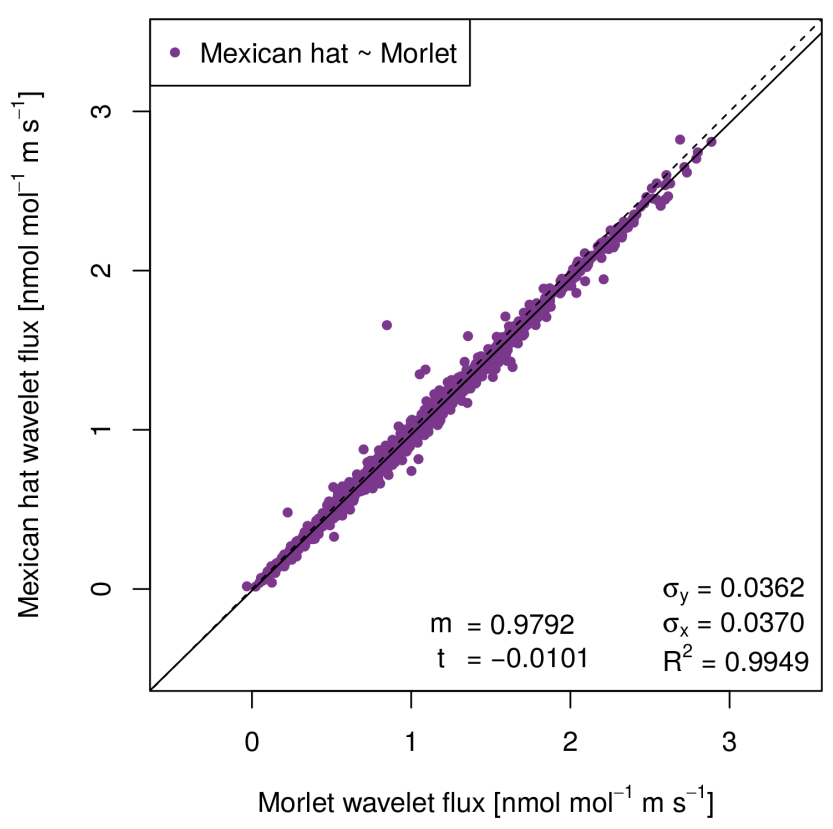

Figure 2. Scatterplot of Morlet against Mexican hat wavelet methane flux (right) for times with best steady-state conditions and well-developed turbulence. The dashed line follows the function $f(x)=x$ and the solid one is the orthogonal regression line.

To sum up, the method developed and implemented in this study to obtain methane fluxes using wavelet analysis agreed very well with the eddy covariance results under best steadystate conditions and well-developed turbulence. Both methods resulted in a small, but detectable underestimation of the flux, where the use of the Morlet wavelet marginally showed better results. This is due to its excellent frequency resolution and in agreement with other authors who also applied or recommended the Morlet wavelet on atmospheric turbulence time series (e.g. Farge, 1992; Mauder et al., 2007a; Thomas and Foken, 2007; Charuchittipan et al., 2014). In contrast, the Mexican hat flux showed a marginally greater deviation, but is nonetheless within the typical error range of eddy covariance. Thus the Mexican hat wavelet is suitable especially for a high temporal resolution of the flux. If the Morlet wavelet shows large flux contributions in the low-frequency range, the necessity of a correction should be tested with the ogive test (Desjardins et al., 1989; Oncley et al., 1990). According to own investigations (Foken et al., 2006; Charuchittipan et al., 2014), flux contributions of periods exceeding $30 \mathrm{~min}$ are very small, and usually only become relevant in the transition time from day to night and reverse, when all fluxes are very low.

\subsection{Case studies}

\subsubsection{Fully developed turbulence}

In order to discover a situation under well-developed turbulence and best steady-state conditions, the afternoon of 23 July 2014 from 13:00 to 16:00 was chosen as a random example (Fig. 4). The atmospheric stratification was unstable and the friction velocity ranged around $0.4 \mathrm{~ms}^{-1}$ with only very low variance over time. Also the mean wind speed was almost constant over time with a mean of $4.7 \mathrm{~ms}^{-1}$, i.e. a gentle breeze coming from north to northwest. The afternoon was sunny with only a few high clouds; thus, the absolute value of the short-wave down-welling radiation reached its maximum at $676 \mathrm{Wm}^{-2}$ in the late noon at 13:30 and decreased afterwards continuously to $590 \mathrm{Wm}^{-2}$ at the end of the example period. The high solar radiation led to a warming of the surface and therefore to an increasing air temperature caused by the sensible heat flux as well as to decreasing relative humidity over the investigated time interval. The wavelet crossscalograms did not show any signs of irregularities which could have been caused by sudden events, while eddy covariance and wavelet fluxes almost perfectly coincided. Referring to the $30 \mathrm{~min}$ average, the Morlet wavelet always showed a greater methane flux by 0.01 to $0.03 \mathrm{nmol} \mathrm{mol}^{-1} \mathrm{~m} \mathrm{~s}^{-1}$ than the Mexican hat. In comparison of the Morlet wavelet flux to eddy covariance, there were only differences by -0.02 to $0.03 \mathrm{nmol} \mathrm{mol}^{-1} \mathrm{~m} \mathrm{~s}^{-1}$ and therefore it can be said that the Morlet flux resulted in a better accordance than the Mexican hat - this is also in agreement to the general findings in Sect. 3.1.

In contrast to the very good agreement of wavelet and eddy covariance fluxes, the conditional sampling results showed a non-systematic deviation from the latter flux type by -0.10 to $0.18 \mathrm{nmol} \mathrm{mol}^{-1} \mathrm{~m} \mathrm{~s}^{-1}$. As already discussed, a substantial meteorological reason for that deviations was not found. Assuming a small error of only $\pm 1 \times 10^{-4} \mathrm{~ms}^{-1}$ in the correct determination of $\bar{w}$ (turquoise error bars in Fig. 4, bottom plot) was enough to explain the found variability, i.e. the method is highly sensitive to the correct estimation of the mean vertical wind speed.

\subsubsection{Short-time turbulent event}

Filtering the $1 \mathrm{~min}$ averaged wavelet flux as described in Sect. 2.8, several mostly nocturnal short-time turbulent events were found. One of these occurred in the night from 2 to 3 August 2014 (Fig. 5). It was a clear night with initially only a light breeze with a maximum around $1.5 \mathrm{~m} \mathrm{~s}^{-1}$, which decreased to a calm situation around 23:30. After that with upcoming turbulence the methane concentration increased rapidly by more than $500 \mathrm{nmol} \mathrm{mol}^{-1}$ around midnight. At 23:59 the 1 min wavelet flux consequently increased rapidly from 1.9 up to $6.8 \mathrm{nmol} \mathrm{mol}^{-1} \mathrm{~m} \mathrm{~s}^{-1}$ - this is the beginning of the event, which lasted until 00:07. Exactly in the time in- 

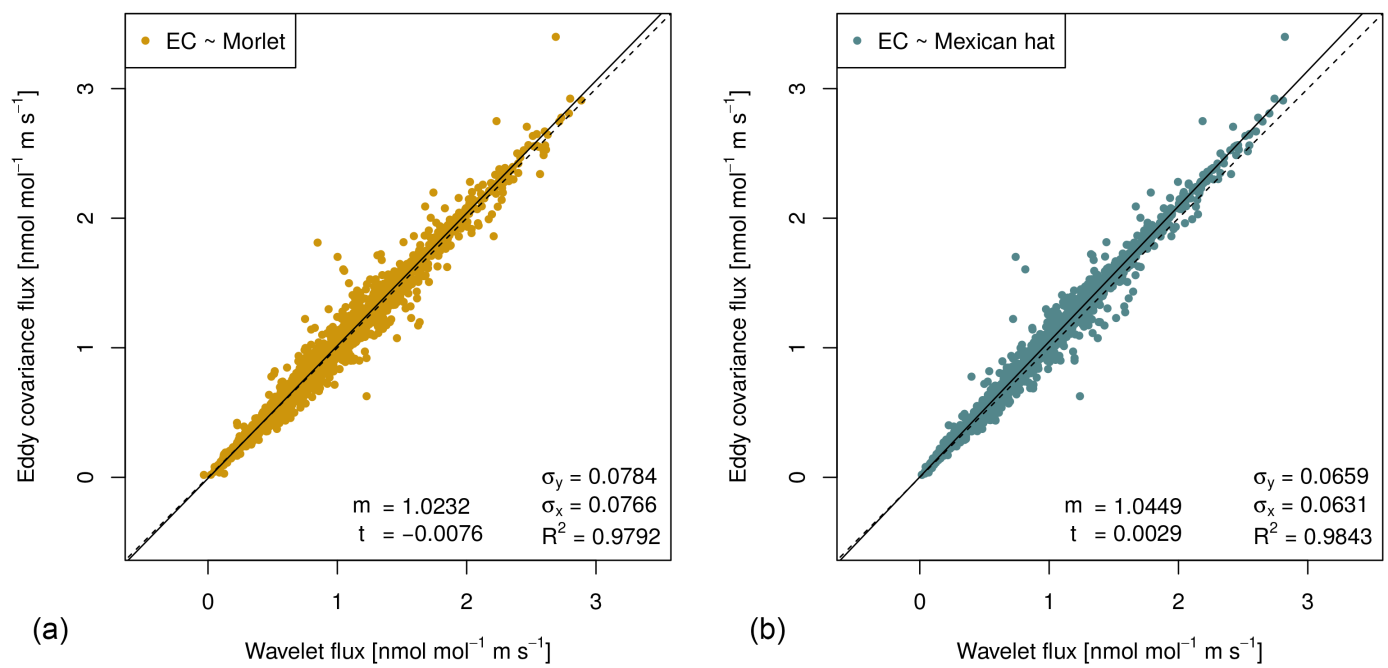

Figure 3. Scatterplot of Morlet (left) and Mexican hat wavelet methane flux (right) against eddy covariance for times with best steady-state conditions and well-developed turbulence. The dashed line follows the function $f(x)=x$ and the solid one is the mean regression line.

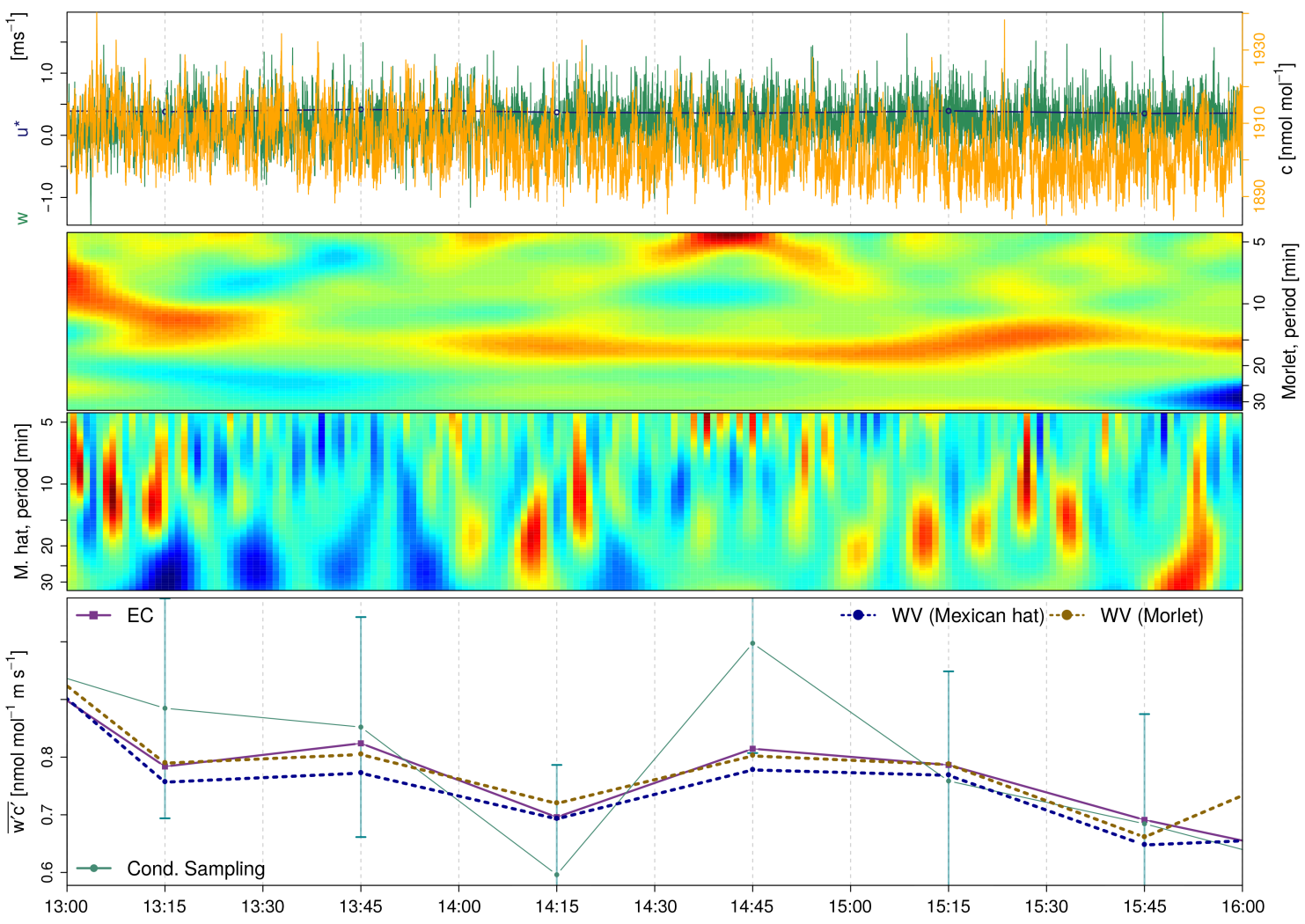

Figure 4. Case study of 23 July 2014. The colours in the wavelet cross-scalograms between $w$ and $c$ denote the flux intensity: blue refers to the smallest, green to medium and red to highest methane flux contributions. The cone of influence is outside of the scalogram, i.e. it was not affected by border effects. The third panel shows the $30 \mathrm{~min}$ fluxes determined using the classical eddy covariance method (EC) and the conditional sampling method as well as the 1 min fluxes of the wavelet method averaged on the same 30 min interval as the other fluxes. The error bars for conditional sampling display the range of the result for $\bar{w} \pm 10^{-4} \mathrm{~ms}^{-1}$. 


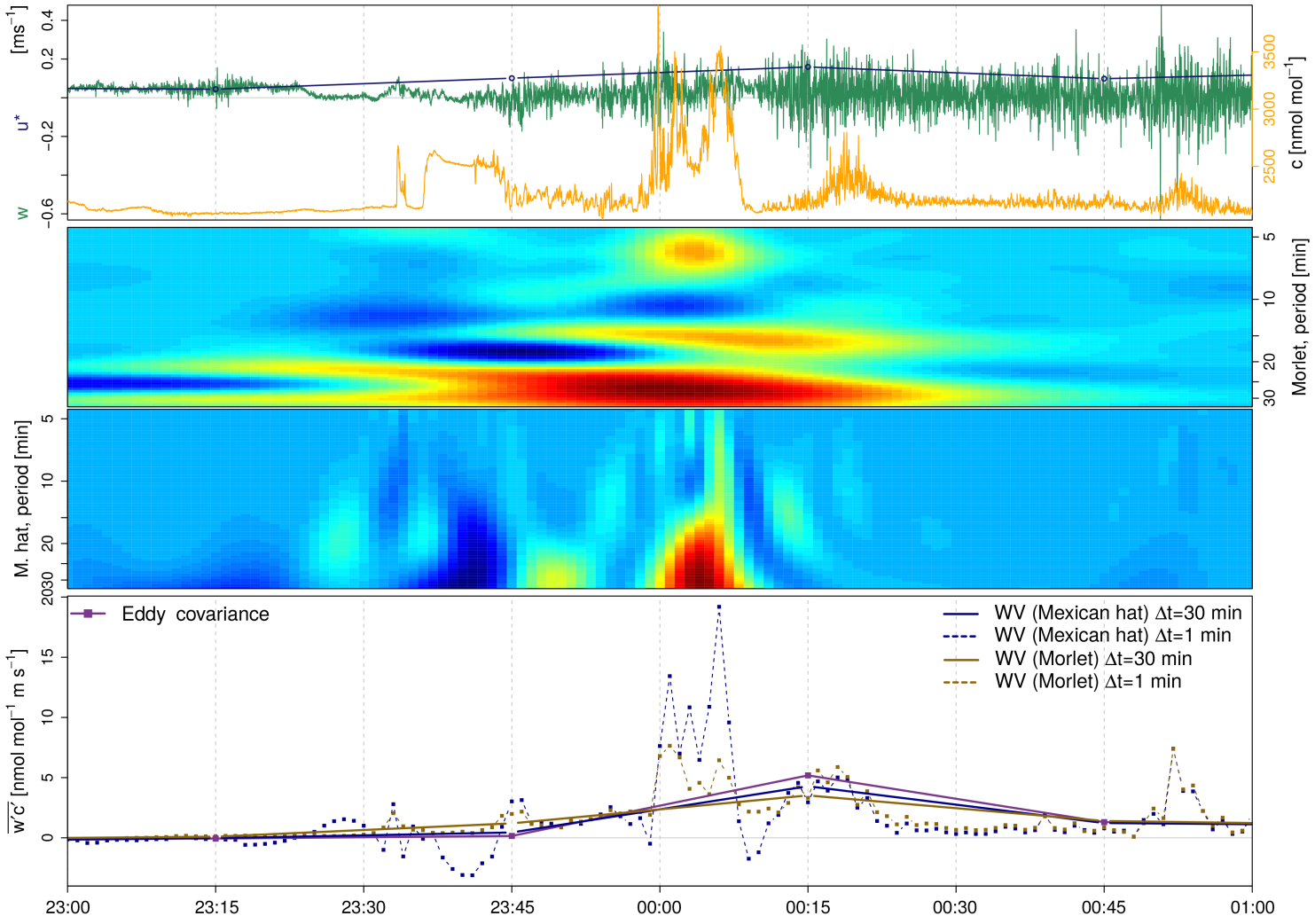

Figure 5. Case study of 2/3 August 2014. The colours in the wavelet cross-scalograms between $w$ and $c$ denote the flux intensity: blue refers to the smallest, green to medium and red to highest methane flux contributions. The cone of influence is outside of the scalogram, i.e. it was not affected by border effects. The third panel shows in solid lines the 30 min fluxes determined using the classical eddy covariance method as well as the $1 \mathrm{~min}$ fluxes of the wavelet method averaged on the same $30 \mathrm{~min}$ interval. Dashed lines represent wavelet fluxes with an averaging period of $1 \mathrm{~min}$.

terval 23:30 to 23:59, where the event begin was detected, the (half hourly calculated) friction velocity $u_{*}$ also increased up to $0.1 \mathrm{~ms}^{-1}$. Both methane concentration and friction velocity decreased afterwards.

In the same time during the event the eddy covariance flux quality was determined to be very low following the overall quality flag system by Foken et al. (2004). This is due to the violation of the steady-state assumption (Foken and Wichura, 1996). The conditional sampling flux was nearly equal to the eddy covariance flux, but due to its dependency of the mean vertical wind (Sect. 3.1.1), it is not reliable here.

As wavelet analysis does not require steady-state conditions, the obtained wavelet results are the most trustworthy fluxes. The wavelet flux over $30 \mathrm{~min}$ was about $1.0 \mathrm{nmol} \mathrm{mol}^{-1} \mathrm{~m} \mathrm{~s}^{-1}$ (Morlet) to $1.5 \mathrm{nmol} \mathrm{mol}^{-1} \mathrm{~m} \mathrm{~s}^{-1}$ (Mexican hat) smaller than the eddy covariance result. Using an averaging period of $1 \mathrm{~min}$, the Mexican hat flux showed greater peaks than the Morlet version. This difference in results between the two wavelets was due to their characteristic properties: the Mexican hat flux allowed an exact localization of the event in time under consideration of an indistinct resolution in frequency domain. On the other hand the Morlet flux resolves the flux contributions in frequency domain best, but the time domain resolution is not precise. In consequence, only the Mexican hat wavelet was able to resolve the event exactly in time, while the Morlet wavelet results should be more trustworthy in order to obtain the flux balance over a longer time, e.g. $30 \mathrm{~min}$.

As this study aims on a methodological comparison, the meteorological and ecological discussion of this event will be presented in a future paper.

\section{Conclusions}

The aim of the present study was to develop a software, which calculates the flux from $20 \mathrm{~Hz}$ wind and methane concentration data in order to resolve and investigate peaks in flux of only short duration within minutes properly. Under best steady-state conditions and well-developed turbulence it was found that the $30 \mathrm{~min}$ averaged results of the developed routine based on wavelet analysis were in very good agreement with eddy covariance. This also implies that the wavelet results itself might be used as reference flux in future studies. For conditional sampling a high sensitivity re- 
garding the correct choice of $w$ could be shown, which led to a non-negligible number of outliers. Ignoring these spikes, a satisfactory agreement to eddy covariance was determined, but the unsystematic errors made the results critical for detailed investigations. Conditional sampling may be applied for nearly steady-state data sets and can be used as a tool to see the effects of periodic coherent structures on the flux as was done by Thomas and Foken (2007) or to analyse the coefficients for relaxed eddy accumulation (Riederer et al., 2014).

Eddy covariance is the standard method for flux investigation on ecosystem scale. But in the case of short-time turbulent events, it typically results in a flux of bad quality due to a violation of the steady-state assumptions over the averaging period. Exactly in such situations, the wavelet method provided a more trustworthy flux, because it does not require steady-state conditions. The Mexican hat flux allowed an exact localization of the event in time, while the Morlet flux resolves the flux contributions in frequency domain best. If the Morlet wavelets indicates large flux contributions for low frequencies, these time series should be controlled or even corrected with the ogive method. Therefore, the Mexican hat wavelet flux offers the possibility of a detailed analysis of non-stationary times, where the classical eddy covariance method fails. Additionally, the Morlet wavelet should be used to provide a trustworthy flux in those 30 min periods where eddy covariance led to low quality due to instationarities.

In the next stage of this project, we will evaluate the performance of eddy covariance and wavelet methods to detect fluxes under different types of non-steady-state events, which are typically observed during long-term flux monitoring campaigns for $\mathrm{CH}_{4}$. The overall objective here will be to evaluate whether or not a significant portion of $\mathrm{CH}_{4}$ emissions is missed by the eddy covariance method, because short-term events are regularly discarded from the flux budget because of the resulting very low data quality related to non-steady-state conditions.

\section{Data availability}

The dataset containing all necessary data to calculate methane fluxes for both case studies is publicly available at: https://doi.pangaea.de/10.1594/PANGAEA.873260 (Schaller et al., 2017).

Competing interests. The authors declare that they have no conflict of interest.

Acknowledgements. This work has been supported by the European Commission (PAGE21 project, FP7-ENV-2011, grant agreement no. 282700, and PerCCOM project, FP7-PEOPLE-2012-CIG, grant agreement no. PCIG12-GA-2012-333796), the German Ministry of Education and Research (CarboPerm project, BMBF grant no. 03G0836G), and the AXA Research Fund (PDOC_2012_W2 campaign, ARF fellowship M. Göckede). Furthermore the German Academic Exchange Service (DAAD) gave financial support for travel expenses. We thank Fanny Kittler, who greatly assisted the research.

The article processing charges for this open-access publication were covered by the Max Planck Society.

Edited by: S. Malinowski

Reviewed by: two anonymous referees

\section{References}

Antonia, R. A.: Conditional sampling in turbulence measurement, Annu. Rev. Fluid. Mech., 13, 131-56, 1981.

Aubinet, M., Vesala, T., and Papale, D. (Eds.): Eddy covariance: a practical guide to measurement and data analysis, Springer, Dordrecht, 2012.

Charuchittipan, D., Babel, W., Mauder, M., Leps, J.-P., and Foken, T.: Extension of the Averaging Time in Eddy-Covariance Measurements and Its Effect on the Energy Balance Closure, Bound.Lay. Meteorol., 152, 303-327, doi:10.1007/s10546-014-9922-6, 2014.

Collineau, S. and Brunet, Y.: Detection of turbulent coherent motions in a forest canopy part I: Wavelet analysis, Bound.-Lay. Meteorol., 65, 357-379, 1993a.

Collineau, S. and Brunet, Y.: Detection of turbulent coherent motions in a forest canopy part II: Time-scales and conditional averages, Bound.-Lay. Meteorol., 66, 49-73, doi:10.1007/BF00705459, 1993 b.

Desjardins, R. L.: Description and evaluation of a sensible heat flux detector, Bound.-Lay. Meteorol., 11, 147-154, doi:10.1007/BF02166801, 1977.

Desjardins, R. L., MacPherson, J. I., Schuepp, P. H., and Karanja, F.: An evaluation of aircraft flux measurements of $\mathrm{CO}_{2}$, water vapor and sensible heat, Bound.-Lay. Meteorol., 47, 55-69, doi:10.1007/BF00122322, 1989.

Dunn, G.: Statistical evaluation of measurement errors, Arnold, London, 2 edn., 2004.

Farge, M.: Wavelet Transforms and their Applications to Turbulence, Annu. Rev. Fluid. Mech., 24, 395-458, doi:10.1146/annurev.fl.24.010192.002143, 1992.

Finnigan, J. J., Clement, R., Malhi, Y., Leuning, R., and Cleugh, H.: A Re-Evaluation of Long-Term Flux Measurement Techniques Part I: Averaging and Coordinate Rotation, Bound.-Lay. Meteorol., 107, 1-48, 2003.

Foken, T.: Micrometeorology, Springer, Berlin, 2nd edn., 2016.

Foken, T. and Wichura, B.: Tools for quality assessment of surfacebased flux measurements, Agr. Forest. Meteorol., 78, 83-105, doi:10.1016/0168-1923(95)02248-1, 1996.

Foken, T., Göckede, M., Mauder, M., Mahrt, L., Amiro, B., and Munger, W.: Post-Field Data Quality Control, in: Handbook of Micrometeorology, edited by: Lee, X., Massman, W., and Law, B., 181-208, Kluwer, Dordrecht, 2004.

Foken, T., Wimmer, F., Mauder, M., Thomas, C., and Liebethal, C.: Some aspects of the energy balance closure problem, At- 
mos. Chem. Phys., 6, 4395-4402, doi:10.5194/acp-6-4395-2006, 2006.

Foken, T., Aubinet, M., and Leuning, R.: The eddy covariance method, in: Eddy covariance: a practical guide to measurement and data analysis, edited by: Aubinet, M., Vesala, T., and Papale, D., Springer Atmospheric Sciences, 1-19, Springer, Dordrecht, 2012.

Fratini, G. and Mauder, M.: Towards a consistent eddy-covariance processing: an intercomparison of EddyPro and TK3, Atmos. Meas. Tech., 7, 2273-2281, doi:10.5194/amt-7-2273-2014, 2014.

Gouhier, T.: biwavelet: Conduct univariate and bivariate wavelet analyses, Library for R, Version 0.17.2, available at: https://cran. r-project.org/package=biwavelet (last access: September 2014), 2014.

Handorf, D. and Foken, T.: Analysis of turbulent structure over an Antarctic ice shelf by means of wavelet transformation. $12^{\text {th }}$ Symosium on Boundary Layer and Turbulence, American Meteorological Society, 245-246, 1997.

Hoaglin, D. C., Mosteller, F., and Tukey, J. W.: Understanding robust and exploratory data analysis, John Wiley \& Sons, New York, 2000.

Hollander, M. and Wolfe, D. A.: Nonparametric Statistical Methods, John Wiley \& Sons, New York, 1973.

Hudgins, L., Friehe, C. A., and Mayer, M. E.: Wavelet transforms and atmopsheric turbulence, Phys. Rev. Lett., 71, 3279-3282, 1993.

Katul, G. G. and Parlange, M. B.: Analysis of land-surface heat fluxes using the orthonormal wavelet approach, Water Resour. Res., 31, 2743-2749, doi:10.1029/95WR00003, 1995.

Kolle, O. and Rebmann, C.: EddySoft - Documentation of a Software Package to Acquire and Process Eddy Covariance Data, Technical Report Nr. 10. Max-Planck-Institute for Biogeochemistry, Jena, 2007.

Kumar, P. and Foufoula-Georgiou, E.: Wavelet analysis for geophysical applications, Rev. Geophys., 35, 385-412, doi:10.1029/97RG00427, 1997.

Mahrt, L.: Eddy asymmetry in the sheared heated boundary layer, J. Atmos. Sci., 48, 472-492, doi:10.1175/15200469(1991)048<0472:EAITSH>2.0.CO;2, 1991.

Mauder, M. and Foken, T.: Documentation and Instruction Manual of the Eddy-Covariance Software Package TK3 (update), available at: https://epub.uni-bayreuth.de/2130/, work report, University of Bayreuth, Department of Micrometeorology, 62, 2015a.

Mauder, M. and Foken, T.: Eddy-Covariance software TK3, Zenodo, doi:10.5281/zenodo.20349, 2015 b.

Mauder, M., Liebethal, C., Göckede, M., Leps, J.-P., Beyrich, F., and Foken, T.: Processing and quality control of flux data during LITFASS-2003, Bound.-Lay. Meteorol., 121, 67-88, doi:10.1007/s10546-006-9094-0, 2006.

Mauder, M., Desjardins, R. L., Oncley, S. P., and MacPherson, I.: Atmospheric response to a partial solar eclipse over a cotton field in central California, J. Appl. Meteor. Climatol., 46, 1792-1803, doi:10.1175/2007JAMC1495.1, 2007a.

Mauder, M., Oncley, S. P., Vogt, R., Weidinger, T., Ribeiro, L., Bernhofer, C., Foken, T., Kohsiek, W., De Bruin, H. A. R., and Liu, H.: The energy balance experiment EBEX-2000. Part II: Intercomparison of eddy-covariance sensors and post-field data processing methods, Bound.-Lay. Meteorol., 123, 29-54, doi:10.1007/s10546-006-9139-4, 2007b.

Mauder, M., Foken, T., Clement, R., Elbers, J. A., Eugster, W., Grünwald, T., Heusinkveld, B., and Kolle, O.: Quality control of CarboEurope flux data - Part 2: Inter-comparison of eddy-covariance software, Biogeosciences, 5, 451-462, doi:10.5194/bg-5-451-2008, 2008.

Moore, C.: Frequency response corrections for eddy correlation systems, Bound.-Lay. Meteorol., 37, 17-35, doi:10.1007/BF00122754, 1986.

Nordbo, A. and Katul, G.: A Wavelet-Based Correction Method for Eddy-Covariance High-Frequency Losses in Scalar Concentration Measurements, Bound.-Lay. Meteorol., 146, 81-102, 2013.

Oncley, S. P., Businger, J. A., Itsweire, E. C., Friehe, C. A., LaRue, J. C., and Chang, S. S.: Surface layer profiles and turbulence measurements over uniform land under near-neutral conditions, in: 9th Symp on Boundary Layer and Turbulence, 237-240, American Meteorological Society, Roskilde, Denmark, 1990.

Papale, D., Reichstein, M., Aubinet, M., Canfora, E., Bernhofer, C., Kutsch, W., Longdoz, B., Rambal, S., Valentini, R., Vesala, T., and Yakir, D.: Towards a standardized processing of Net Ecosystem Exchange measured with eddy covariance technique: algorithms and uncertainty estimation, Biogeosciences, 3, 571-583, doi:10.5194/bg-3-571-2006, 2006.

Percival, D. and Walden, A. T.: Wavelet methods for time series analysis, Cambridge Univ. Press, Cambridge, 2008.

Rebmann, C., Kolle, O., Heinesch, B., Queck, R., Ibrom, A., and Aubinet, M.: Data Acquisition and Flux Calculations, in: Eddy covariance: a practical guide to measurement and data analysis, edited by: Aubinet, M., Vesala, T., and Papale, D., Springer Atmospheric Sciences, 59-84, Springer, Dordrecht, 2012.

Riederer, M., Hübner, J., Ruppert, J., Brand, W. A., and Foken, T.: Prerequisites for application of hyperbolic relaxed eddy accumulation on managed grasslands and alternative net ecosystem exchange flux partitioning, Atmos. Meas. Tech., 7, 4237-4250, doi:10.5194/amt-7-4237-2014, 2014.

Saito, M. and Asanuma, J.: Eddy Covariance Calculation Revisited with Wavelet Cospectra, Sola, 4, 49-52, doi:10.2151/sola.2008013, 2008.

Schaller, C., Göckede, M., and Foken, T.: Flux calculation of short turbulent events in Chersky in the Sakha (Yakutia) Republic, Far Eastern Federal District of Russia, available at: https://doi. pangaea.de/10.1594/PANGAEA.873260, 2017.

Schotanus, P., Nieuwstadt, F., and De Bruin, H.: Temperature measurement with a sonic anemometer and its application to heat and moisture fluxes, Bound.-Lay. Meteorol., 26, 81-93, doi:10.1007/BF00164332, 1983.

Strunin, M. A. and Hiyama, T.: Applying wavelet transforms to analyse aircraft-measured turbulence and turbulent fluxes in the atmospheric boundary layer over eastern Siberia, Hydrol. Process., 18, 3081-3098, doi:10.1002/hyp.5750, 2004.

Stull, R. B.: An Introduction to Boundary Layer Meteorology, Kluwer Acad. Publ., Dordrecht, Boston, London, 1988.

Terradellas, E., Morales, G., Cuxart, J., and Yagüe, C.: Wavelet methods: application to the study of the stable atmospheric boundary layer under non-stationary conditions, Dynam. Atmos. Oceans, 34, 225-244, doi:10.1016/S0377-0265(01)000690,2001 
Thomas, C. K. and Foken, T.: Detection of long-term coherent exchange over spruce forest using wavelet analysis, Theor. Appl. Climatol., 80, 91-104, doi:10.1007/s00704-004-0093-0, 2005.

Thomas, C. K. and Foken, T.: Flux contribution of coherent structures and its implications for the exchange of energy and matter in a tall spruce canopy, Bound.-Lay. Meteorol., 123, 317-337, doi:10.1007/s10546-006-9144-7, 2007.

Torrence, C. and Compo, G. P.: A Practical Guide to Wavelet Analysis, B. Am. Meteorol. Soc., 79, 61-78, doi:10.1175/15200477(1998)079<0061:APGTWA>2.0.CO;2, 1998.
Treviño, G. and Andreas, E. L.: On wavelet analysis of nonstationary turbulence, Bound.-Lay. Meteorol., 81, 271-288, doi:10.1007/BF02430332, 1996.

Webb, E. K., Pearman, G. I., and Leuning, R.: Correction of flux measurements for density effects due to heat and water vapour transfer, Q. J. Roy. Meteor. Soc., 106, 85-100, doi:10.1002/qj.49710644707, 1980.

Wilczak, J. M., Oncley, S. P., and Stage, S. A.: Sonic Anemometer Tilt Correction Algorithms, Bound.-Lay. Meteorol., 99, 127150, doi:10.1023/A:1018966204465, 2001. 